\title{
Glycoprotein 130 Signaling Regulates Notch1 Expression and Activation in the Self-Renewal of Mammalian Forebrain Neural Stem Cells
}

\author{
Andrew Chojnacki, ${ }^{1}$ Takuya Shimazaki, ${ }^{1}$ Christopher Gregg, ${ }^{1}$ Gerry Weinmaster, ${ }^{2}$ and Samuel Weiss ${ }^{1}$ \\ ${ }^{1}$ Genes \& Development Research Group, Department of Cell Biology and Anatomy, University of Calgary, Faculty of Medicine, Calgary, Alberta, Canada T2N \\ 4N1, and ${ }^{2}$ Department of Biological Chemistry, Molecular Biology Institute, University of California at Los Angeles School of Medicine, Los Angeles, \\ California 90095-1737
}

Glycoprotein 130 (gp130) and Notch signaling are thought to participate in neural stem cell (NSC) self-renewal. We asked whether gp 130 regulates Notch activity in forebrain epidermal growth factor (EGF)-responsive NSCs. Disruption of Notch1 using antisense or a $\gamma$-secretase inhibitor demonstrated a requirement for Notchl in the maintenance and proliferation of NSCs. Ciliary neurotrophic factor (CNTF) activation of gp130 in NSCs rapidly increased Notch1 expression. NOTCH1 activation, indicated by tumor necrosis factor $\alpha$-converting enzyme (TACE)- and presenilin-mediated processing, also increased. Infusion of EGF + CNTF into adult forebrain lateral ventricles increased periventricular NOTCH1 compared with EGF alone. Neither Hes1 (hairy and enhancer of split) nor Hes5 appeared to mediate gp130-enhanced NOTCH1 signaling that regulates NSC maintenance. This is the first example of a link between gp130 signaling and NOTCH1 in regulating NSC self-renewal.

Key words: notch; gp130; CNTF; stem cell; delta; self-renewal

\section{Introduction}

Two principal characteristics of neural stem cells (NSCs) are multipotency and self-renewal, the ability to maintain this multipotency after repeated rounds of proliferation (for review, see Gage, 2000; Alvarez-Buylla et al., 2000). In the adult mammalian CNS, a population of NSCs reside in the periventricular area of the forebrain lateral ventricles (Reynolds and Weiss, 1992; Morshead et al., 1994) and contribute neurons to the olfactory bulb throughout adulthood (Lois and AlvarezBuylla, 1994; Doetsch and Alvarez-Buylla, 1996). It is likely that epidermal growth factor (EGF) or transforming growth factor (TGF) $\alpha$ is the in vivo mitogen for adult forebrain NSCs (Reynolds et al., 1992; Morshead et al., 1994; Tropepe et al., 1997; Doetsch et al., 1999). On the other hand, little is known about the epigenetic regulation of NSC self-renewal.

Glycoprotein 130 (gp130) mediates signaling initiated by the cytokine class of secreted factors, which include leukemia inhibitory factor (LIF), ciliary neurotrophic factor (CNTF), oncostatin $\mathrm{M}$, and interleukin-6 (IL-6), among others (for review, see Turnley and Bartlett, 2000). LIF signals through the dimerization of its cognitive receptor, LIF receptor $\beta$ (LIFR $\beta$ ), with gp 130 , whereas CNTF signaling is mediated by a heterotrimeric complex consist-

Received June 24, 2002; revised Dec. 6, 2002; accepted Dec. 9, 2002.

This work was supported by the Canadian Institutes of Health Research. C.G. is supported by a studentship from the Multiple Sclerosis Foundation of Canada. S.W. is an Alberta Heritage Foundation for Medical Research Scientist. We thank Dorothea Livingstone for excellent technical assistance and Dr. Carol Schuurmans for critical review of an earlier version of this manuscript.

Correspondence should be addressed to Samuel Weiss, Genes \& Development Research Group, Department of Cell Biology and Anatomy, University of Calgary, Faculty of Medicine, Calgary, Alberta, Canada T2N 4N1. E-mail: weiss@ucalgary.ca.

T. Shimazaki's present address: Department of Physiology, Keio University School of Medicine, 35 Shinanomachi, Shinjyuku-ku Tokyo, 160-8582 Japan.

Copyright $\odot 2003$ Society for Neuroscience $\quad$ 0270-6474/03/231730-12\$15.00/0 ing of CNTF receptor $\alpha(\mathrm{CNTFR} \alpha)$, LIFR $\beta$, and gp130 subunits. The long-term maintenance of embryonic stem (ES) cells and NSCs requires the presence of LIF or CNTF (Smith et al., 1988; Williams et al., 1988; Conover et al., 1993; Carpenter et al., 1999; Shimazaki et al., 2001). We recently reported that CNTF signaling (through the CNTF/LIF/gp130 receptor complex) acts to maintain embryonic and adult NSCs in an undifferentiated state by blocking NSC differentiation to restricted glial precursors, with no action on stem cell survival or proliferation (Shimazaki et al., 2001). The mechanisms underlying the actions of CNTF on NSC self-renewal are not understood.

Notch signaling has also been implicated in NSC maintenance (for review, see Artavanis-Tsakonas et al., 1999). Deletion of the basic helix-loop-helix (bHLH) transcriptional repressor Hes 1 (hairy and enhancer of split), a known mediator of Notch signaling, causes premature neuronal progenitor cell differentiation and a reduction in the self-renewal capacity of embryonic forebrain NSCs (Nakamura et al., 2000). Overexpression of activated $\mathrm{NOTCH} 1$ in the embryonic cortex results in an increase of radial glial cells (Gaiano et al., 2000), which have been implicated in neurogenesis (for review, see Alvarez-Buylla et al., 2001). Recently, Hitoshi et al. (2002) demonstrated that Notch signaling was required for the maintenance of NSCs but not their generation; however, Notch signaling appears to be context dependent and can also promote glial cell fate (Morrison et al., 2000; Chambers et al., 2001).

Given the context-dependent nature of Notch signaling, we first tested whether it functioned in the maintenance of NSCs derived from the basal forebrain. We then tested the hypothesis that gp130 signaling regulates NSC self-renewal by regulating Notch signaling. Our in vitro and in vivo data support the conclusions that NOTCH1 
signaling functions in NSC maintenance and proliferation and that activation of gp130 leads to an increase in NOTCH1 signaling.

\section{Materials and Methods}

Animals and genotyping. Breeding and genotyping of LIFR mice has been described previously (Shimazaki et al., 2001). CD1 mice were obtained from the University of Calgary Animal Resources Center (Calgary, Alberta, Canada).

Cell culture. Generation of primary and secondary embryonic day 14 (E14) striatal neurospheres was performed as described previously (Shimazaki et al., 2001). Briefly, dissociated primary neurospheres were cultured at a density of $0.05 \times 10^{6}$ cells $/ \mathrm{ml}$ in culture flasks containing either EGF alone or EGF and rat CNTF [ $20 \mathrm{ng} / \mathrm{ml}$; Peprotech (Rocky Hill, $\mathrm{NJ}$ ) and gift from Dr. Rob Dunn (McGill University), respectively], unless stated otherwise. Additionally, IL-6 and soluble IL-6 receptor (sIL6R) (both from R\&D, Minneapolis, MN) were used at 20 and 25 $\mathrm{ng} / \mathrm{ml}$, respectively. Cells were cultured for a maximum of $7 \mathrm{~d}$ in vitro (DIV) and harvested for various molecular and biochemical analyses stated below. For NOTCH1 immunoreactive cell counts, primary neurospheres were dissociated and cultured at 50,000 cells $/ \mathrm{ml}$ for $6 \mathrm{hr}$ in either EGF or EGF+CNTF on poly-L-ornithine-coated coverslips and processed for NOTCH1 immunocytochemistry as stated below.

RT-PCR-Southern blot. Total RNA was isolated from neurospheres using Trizol reagent (Invitrogen, Carlsbad, CA). First-strand cDNA was synthesized using Superscript RT (Invitrogen) at an incubation time of $75-90 \mathrm{~min}$ at $42^{\circ} \mathrm{C}$. RT-PCR analysis was used to establish the presence of Notch1, -2, -3, -4, Delta1 and -3, Jagged 1 and -2, Hes1 and -5, and Mash1 in EGF-derived stem cell progenies using the conditions stated in Table 1. Each product was amplified by denaturation $\left(94^{\circ} \mathrm{C}, 45 \mathrm{sec}\right)$, primer annealing ( $45 \mathrm{sec})$, and extension $\left(72^{\circ} \mathrm{C} 45 \mathrm{sec}\right.$; Jagged 2 , Notch 1 , and Notch 4 for $1 \mathrm{~min})$ with the exception of Delta1, which was a two-step PCR $\left(94^{\circ} \mathrm{C}\right.$ for $45 \mathrm{sec}$ denaturation and anneal at $72^{\circ} \mathrm{C}$ for $1 \mathrm{~min}$ ). Identity of amplified products was established by Southern blot analysis using Notch1, Delta3, Jagged1, Jagged2, and Delta1 (kindly provided by Dr. Domingos Henrique, Lisbon Medical School) cDNA probes or by PCR-based direct cloning and sequencing of Notch2, -3, -4, Jagged1, Hes1, Hes5, and Mash1. PCR products were purified using the Geneclean II kit (BIO 101) and ligated into pGEM-T vector plasmids (Promega, Madison, WI). Sequencing identified correct plasmid clones. Southern blot analysis was performed as described previously (Shimazaki et al., 1999). Experiments were performed at least three times with the exception of RT-PCR analyses, which were performed twice. Pictures were taken on a Kodak DC120 (Rochester, NY) and densitometric analysis was done using Kodak Digital Science 1D software.

Western blotting. Cultured cells were processed for Western blot analysis as described previously (Shimazaki et al., 1999). NucliePURE prep kit (Sigma, St. Louis, MO) was used for the isolation of nuclear proteins as per the manufacturer's instructions. Nitrocellulose membranes were incubated with the 93-4 rabbit $\alpha$ mouse NOTCH1 primary antibody $(1: 10,000)$, or affinity-purified (AFP) goat $\alpha$ mouse NOTCH1 antibody (1:100; Santa Cruz Biotechnology, Santa Cruz, CA), or mouse $\alpha$ mouse MASH1 (1:25; gift from Dr. David Anderson, California Institute of Technology), and/or AFP goat $\alpha$ ACTIN (1:100; Santa Cruz Biotechnology) mouse overnight in the blocking buffer at $4^{\circ} \mathrm{C}$, washed with Trisbuffered saline $(0.1 \%$ Tween 20$)$, and then incubated with blocking buffer plus the appropriate secondary antibody conjugated to horseradish peroxidase (Chemicon, Temecula, CA). Blots were developed using Enhanced Chemiluminescence and Hyperfilm (both from Amersham Biosciences, Baie d'Urfé, Quebec). Pictures and analysis were done as above.

Immunohistochemistry. Mice were processed for immunohistochemistry as described previously (Shimazaki et al., 2001). Coronal cryosections $(8 \mu \mathrm{m})$ of mouse forebrain were double stained for Notch1 and CNTFR as described below. Embryonic sections were postfixed with $100 \%$ acetone for $30 \mathrm{sec}$, preblocked with rabbit IgG Fab2 fragment (Jackson ImmunoResearch, West Grove, PA; 1:100 in 10\% normal donkey serum, $0.4 \%$ Triton X-100, PBS, pH 7.5) for $2 \mathrm{hr}$ at room temperature, incubated overnight at $4^{\circ} \mathrm{C}$ with goat anti-rat CNTFR $\alpha \operatorname{IgG}(1: 100$; Santa Cruz Biotechnology), washed with PBS, incubated for $1 \mathrm{hr}$ at room
Table 1. Primers and PCR conditions for respective genes

\begin{tabular}{|c|c|c|c|c|}
\hline Gene & $\begin{array}{l}\text { Accession number and primers } \\
\left(5^{\prime}-3^{\prime}\right)\end{array}$ & $\begin{array}{l}\text { Annealing } \\
\text { temperature }{ }^{\circ} \mathrm{C}\end{array}$ & $\begin{array}{l}\text { Product size } \\
\text { (bp) }\end{array}$ & $\begin{array}{l}\text { Region } \\
\text { amplified }\end{array}$ \\
\hline Delta1 & $\begin{array}{l}\text { X80903 } \\
\text { cctcgttcgagacctcaagggag s } \\
\text { tagacgtgtgggcagtgcgtgc as }\end{array}$ & 72 & 552 & $1961-2467$ \\
\hline Delta3 & $\begin{array}{l}\text { Y11895 } \\
\text { cacgccattcccagacgagtgcs } \\
\text { gcagtcgtccaggtcgtgct as }\end{array}$ & 58 & 565 & $774-1295$ \\
\hline Jagged1 & $\begin{array}{l}\text { L38483 } \\
\text { cctgccagtgcctgaatggacg s } \\
\text { ggctgtcaccaagcaacagaccc as }\end{array}$ & 61 & 620 & $2913-3532$ \\
\hline Jagged2 & $\begin{array}{l}\text { U70050 } \\
\text { accgtgaccaagtgcctcagggca s } \\
\text { gagcggagcccactggttgttgg as }\end{array}$ & 59 & 485 & $4907-5322$ \\
\hline Notch1 & $\begin{array}{l}\text { Z11886, S47228 } \\
\text { geccagccagtacaacccactacgg s } \\
\text { ggaacggaagctggggtcctgcatc as }\end{array}$ & 62 & 709 & $7029-7687$ \\
\hline Notch2 & $\begin{array}{l}\text { D32210 } \\
\text { caccttgaagctgcagacats } \\
\text { tggtagaccaagtctgtgatgat as }\end{array}$ & 60 & 220 & $5551-5727$ \\
\hline Notch3 & $\begin{array}{l}\text { X74760 } \\
\text { atatatatggagttgctecttccs } \\
\text { ggctttgagcagacaagaccectt as }\end{array}$ & 63 & 307 & $7428-7685$ \\
\hline Notch4 & $\begin{array}{l}\text { U43691 } \\
\text { ggaagcgacacgtacgagtctgg s } \\
\text { caacacceggcacatcgtaggt as }\end{array}$ & 59 & 332 & $6282-6568$ \\
\hline Hes1 & $\begin{array}{l}\text { D16464 } \\
\text { adgcacctccggaacctgcagcs } \\
\text { agtggectgaggctctcagttcc a }\end{array}$ & 65 & 609 & $1092-2278$ \\
\hline Hes5 & $\begin{array}{l}\text { D32132 } \\
\text { gatgcgtcgggaccgcatcaacs } \\
\text { gcagcttcatctgcgtgtcgctg as }\end{array}$ & 61 & 276 & $569-884$ \\
\hline Mash1 & $\begin{array}{l}\text { M95603 } \\
\text { tggagagtggagccggccag s } \\
\text { gcgtcgtgctcgtccagcag as }\end{array}$ & 67 & 504 & $93-556$ \\
\hline$\beta$-actin & $\begin{array}{l}\text { X03672 } \\
\text { cgtgggecgecctaggcaccas } \\
\text { ttggccttagggttcagggggg as }\end{array}$ & $\mathrm{N} / \mathrm{A}$ & 243 & $201-403$ \\
\hline
\end{tabular}

temperature with biotin-conjugated donkey $\alpha$ goat IgG secondary (1: 200; Jackson ImmunoResearch), followed by a $1 \mathrm{hr}$ incubation in streptavidin-Cy3 (1:1000; Jackson ImmunoResearch). Sections were then washed with $\mathrm{PBS}$ and incubated overnight at $4^{\circ} \mathrm{C}$ with rabbit 93-4 anti-rat NOTCH1 (1:25). Sections were then washed and incubated with Hoechst 33258 and goat anti-rabbit fragment crystallisable-specific (1: 100; FITC conjugated) secondary antibody for $30 \mathrm{~min}$ at $37^{\circ} \mathrm{C}$, washed, and mounted with FluorSave (Calbiochem, San Diego, CA). Adult sections were incubated overnight at $4^{\circ} \mathrm{C}$ with rabbit anti-mouse NOTCH1EC (1:50; EC indicates extracellular antibody directed against the extracellular portion of NOTCH1 as named by Dr. Lendahl; gift from Dr. Urban Lendahl, Karolinska Institute) in 5\% NGS, washed with PBS, incubated with biotin-conjugated goat anti-rabbit IgG for $1 \mathrm{hr}$ at room temperature (1:200; Jackson ImmunoResearch), followed by a wash with PBS, incubated with streptavidin-Cy3 as above. Images were taken on a Photometrics Quantix camera (Tucson, AZ) mounted on a Zeiss Axioplan2 (Thornwood, NY) or with a Cohu CCD (San Diego, CA) mounted on a Zeiss Axiovert (for time-lapse images).

Counts of NOTCH1-immunoreactive cells in vitro and in vivo. Dissociated primary spheres, were exposed to either EGF or EGF +CNTF for $6 \mathrm{hr}$ on poly-L-ornithine-coated coverslips. The cells were fixed for $20 \mathrm{~min}$ with $4 \%$ paraformaldehyde at room temperature. Cells were then preblocked in $10 \%$ NGS for $1 \mathrm{hr}$, incubated with NOTCH1EC at 1:2000 overnight at $4^{\circ} \mathrm{C}$, and then incubated with rhodamine-conjugated goat anti-rabbit IgG (Jackson ImmunoResearch). Pictures of five random fields of each condition per independent experiment were taken on a Photometrics Quantix camera mounted on a Zeiss Axioplan2. To cap- 
ture images of NOTCH1 immunoreactivity, all fields were exposed for $1.5 \mathrm{sec}$. Pictures were imported into Adobe Photoshop 4.0. To aid in the distinction between weakly and intensely staining NOTCH1 cells, the brightness was reduced by $150 \%$ in all cases. Blind counts were made on the percentage of intensely immunoreactive NOTCH1-positive cells out of total Hoechst 33258 positive cells. For counts of the number of NOTCH1immunoreactive cells in EGF- and EGF+CNTF-infused animals, six sections (from three independent experiments of EGF and EGF+CNTF infusions) were randomly selected at approximately the same rostral-caudal level, and images of NOTCH1 and Hoechst immunolabeling were captured as above, imported, and pseudocolored in Photoshop 4.0. Respective NOTCH1 and Hoechst panels were overlapped, and $21.6 \mu \mathrm{m}$ (medial-lateral) $\times 173 \mu \mathrm{m}$ (dorsal-ventral) of the expanded lateral ventricle immediately below the dorsal limit was outlined and counted double blind for the number of NOTCH1-immunoreactive cells.

Notch1 antisense and $\gamma$-secretase inhibitor. Oligonucleotides were designed against a portion of the $5^{\prime}$ intracellular cdc10/ankyrin repeat region (CDC) as described previously (Austin et al., 1995). The CDC antisense sequence $5^{\prime}$-CCTCCACTGCAGGAGGCAATCAT-3' was identical to the one described previously with the exception of a G-A (in bold) switch in the mouse sequence. Antisense oligonucleotides were used in parallel with their corresponding sense oligonucleotides at $20 \mu \mathrm{M}$. Briefly, oligonucleotides were added to 2 million dissociated pass 1 (P1) cells in $5 \mathrm{ml}$ of EGF media. Cells were triturated with a fire-polished Pasteur pipette and moved into flasks (Falcon, BDL, Franklin Lakes, NJ); $6 \mathrm{hr}$ later flasks were tapped until cells lifted off the plastic surface. Twenty-four hours later, $4 \mathrm{ml}$ of cells was harvested for Western blot analysis, and the remaining $1 \mathrm{ml}$ was transferred to a six-well plate, and allowed to grow for $3 \mathrm{DIV}$; individual spheres were dissociated in 96-well plates and assayed for the ability to produce secondary spheres after 7 DIV. For the $\gamma$-secretase inhibitor (Calbiochem) experiments, $50 \mu \mathrm{M}$ of the inhibitor was added to 2 million dissociated P1 cells in $5 \mathrm{ml}$ of EGF media, allowed to grow for $24 \mathrm{hr}$, and then harvested for Western blot analysis. For the detection of NOTCH1-protein fragment 2 (PF2), 2 million dissociated P1 cells in $5 \mathrm{ml}$ of EGF were allowed to grow for $24 \mathrm{hr}$, treated with DMSO or $\gamma$-secretase inhibitor $(50 \mu \mathrm{M})$ for $4 \mathrm{hr}$, and then harvested for Western blot analysis. For the detection of NOTCH1-PF3, P1 cells were cultured for 3 DIV at a concentration of $400,000 \mathrm{cells} / \mathrm{ml}$, and then DMSO or $\gamma$-secretase inhibitor II $(50 \mu \mathrm{M})$ was added for $4 \mathrm{hr}$; the cells were then isolated for nuclear proteins as stated above. For the singlesphere dissociation experiments, $\gamma$-secretase II was added to a concentration of $30 \mu \mathrm{M}$, at plating, to dissociated P1 cells in a 24-well plate at a concentration of 400,000 cells/ml. Neurospheres were grown for 3 DIV, and then individual spheres were dissociated in 96-well plates and assayed for secondary neurosphere production. DMSO added to control cultures was equal to the volume of $\gamma$-secretase II inhibitor added.

In vivo growth factor infusions. In vivo infusion of EGF and EGF+CNTF were performed as described in Shimazaki et al. (2001).

\section{Results}

\section{Notch 1 signaling is required for the maintenance of E14} EGF-responsive NSCs

EGF-responsive NSCs of the basal forebrain proliferate to form neurospheres, which contain precursors to neurons, astrocytes, and oligodendrocytes (Reynolds and Weiss, 1996). The in vitro maintenance of an undifferentiated state by NSCs may be studied through the ability of single EGF-generated neurospheres, which are dissociated and cultured in the presence of EGF, to give rise to secondary neurospheres (Reynolds and Weiss, 1996). We recently found that the CNTFR $\alpha / \mathrm{LIFR} \beta /$ gp 130 receptor complex operates in the maintenance of EGF-derived NSCs (Shimazaki et al., 2001). Specifically, when single P1 neurospheres (P1 neurospheres are derived from dissociated primary neurospheres, which in turn are derived from the culture of dissociated E14 striatopallidum complexes in the presence of EGF) generated in the presence of EGF $+\mathrm{CNTF}$ were individually dissociated and replated in EGF alone, they produced $59 \%$ more pass 2 (P2)
A

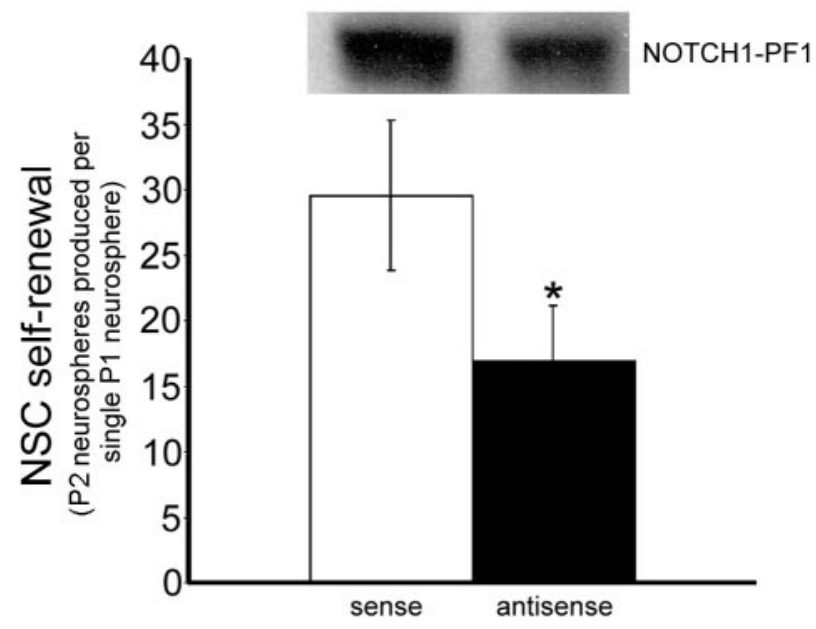

B

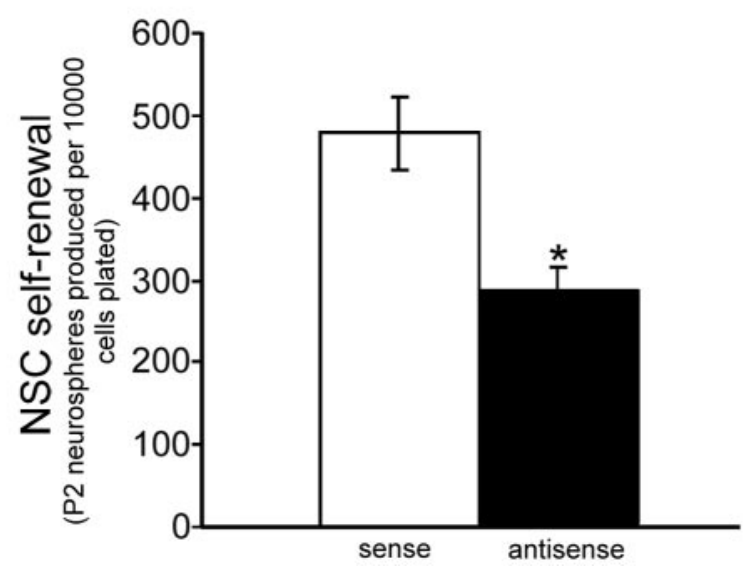

Figure 1. Notch1 antisense reduces NOTCH1 expression and NSC self-renewal. NSCs were cultured in the presence of $20 \mathrm{ng} / \mathrm{ml} \mathrm{EGF}$ in the absence or presence of $20 \mu \mathrm{m}$ Notch 1 antisense and harvested after 1 DIV for protein or cultured for a total of 3 DIV (to form P1 neurospheres) and assayed either by single-sphere dissociation $(A)$ or batch culture $(B)$ for the formation of $P 2$ neurospheres. $A$, Western blot analysis reveals a reduction in NOTCH1-PF1 expression (inset; $p<0.05 ; t$ test; $n=3$ ) in antisense-treated P1 neurospheres. A concomitant decrease was observed in the ability of antisense-treated, individual equivalent sized P1 neurospheres to produce $\mathrm{P} 2$ neurospheres ( ${ }^{*} p<0.05 ; t$ test; $n=3$ ) compared with sense treatment. $B$, Assaying for the ability of $P 1$ neurospheres treated with Notch 1 antisense to produce $P 2$ neurospheres by batch culture analysis also reveals a significant decrease in their ability to produce $P 2$ neurospheres $\left({ }^{*} p<0.05 ; t\right.$ test; $n=3$ ).

neurospheres than equivalent-sized P1 neurospheres generated in EGF and replated in EGF. Before asking whether CNTF could modulate NOTCH1 signaling, we asked whether Notch1 mediates, at least in part, the maintenance of EGF-responsive NSCs. We analyzed the ability of EGF-generated P1 neurospheres to produce $\mathrm{P} 2$ neurospheres after culturing them in the presence of a well characterized antisense to the CDC repeat portion of Notch1 (Austin et al., 1995; Redmond et al., 2000). Exposure of dissociated primary neurospheres to Notch1 antisense $(20 \mu \mathrm{M})$ for their first $24 \mathrm{hr}$ in culture resulted in a significant decrease in $\mathrm{NOTCH} 1$ expression, when compared with cells exposed to sense controls (Fig. 1A). Furthermore, antisense-treated P1 neuro- 


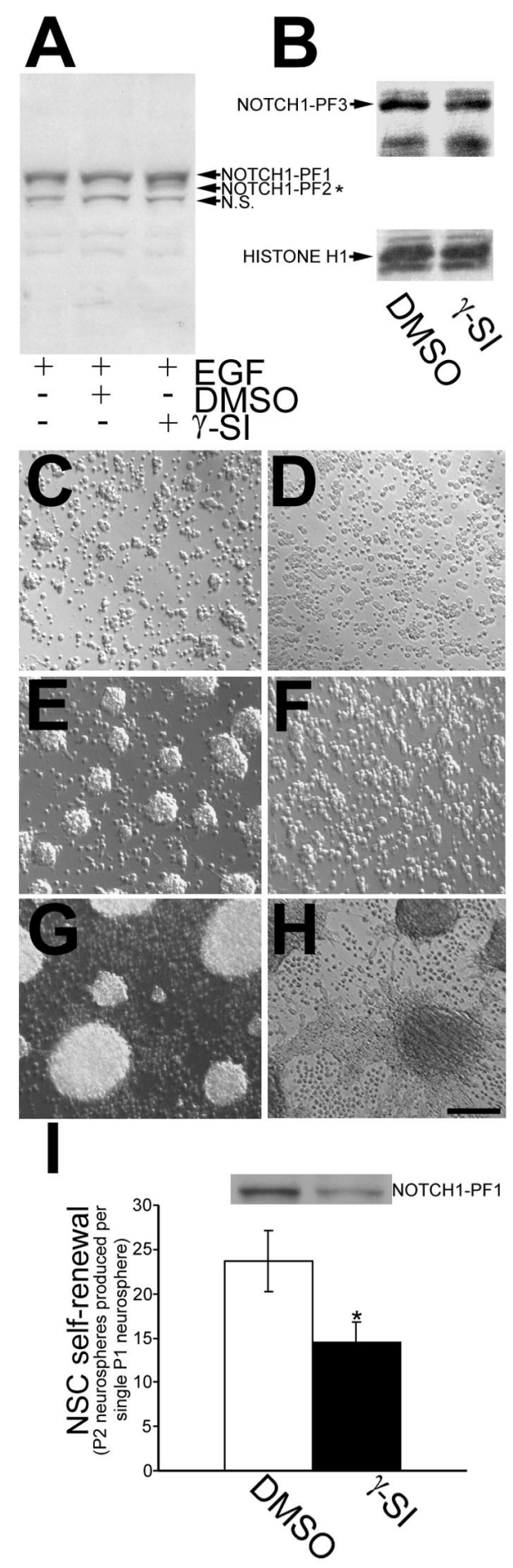

Figure 2. Disruption of NOTCH1 signaling by $\gamma$-secretase inhibitor II delays $\mathrm{P} 1$ neurosphere formation and reduces their ability to produce $\mathrm{P} 2$ neurospheres. $A$, To ensure that the $\gamma$-secretase inhibitor that we were using was effectively blocking production of NOTCH1-PF3, NSCs were cultured in $20 \mathrm{ng} / \mathrm{ml}$ EGF ( $20 \mathrm{ng} / \mathrm{ml}$ ) for $24 \mathrm{hr}$, at which point DMSO (carrier) or $\gamma$-secretase inhibitor II (50 $\mu \mathrm{M})$ was added, and the cells were harvested $4 \mathrm{hr}$ later for total proteins and Western blot analysis. $A$, The asterisk indicates an increase in the $\mathrm{P} 2$ proteolytic product of NOTCH1, as would be expected if the $\gamma$-secretase inhibitor was effectively blocking production of NOTCH1-PF3 ( $n=3)$, and identifies the upper band as furin-processed NOTCH1 or NOTCH1-PF1. B, Three day in vitro P1 neurospheres that were treated with $\gamma$-secretase inhibitor for $4 \mathrm{hr}$ and harvested for nuclear proteins and Western blot analysis demonstrate a decrease in NOTCH1-PF3 compared with DMSO control. C $-H$, NSCs were cultured in EGF $(20 \mathrm{ng} / \mathrm{ml})$ and either DMSO (C, E, G; carrier) or $\gamma$-secretase inhibitor II $(D, F, H ; 30 \mu \mathrm{M})$, and digital micrographs were taken after $6(C, D), 18(E, F)$, and $88 \mathrm{hr}(G, H)$. I, Single-sphere dissociation assay reveals a significant reduction in self-renewal capacity of P1 neurospheres generated for 3 DIV in the spheres had a significantly reduced capacity to produce P2 neurospheres compared with sense controls, whether assayed by single-sphere dissociation of equivalent-sized neurospheres (43\%) (Fig. $1 A$ ) or batch culture experiments (40\%) (Fig. $1 B$ ). These results suggest that NOTCH1 expression levels can regulate the maintenance of EGF-responsive NSCs.

We next sought to determine whether NOTCH1 cleavage/ activation is necessary for the maintenance of EGF-responsive NSCs. A $\gamma$-secretase-like protease has recently been implicated in the cleavage of NOTCH1 into its active intracellular domain (De Strooper et al., 1999) and can be blocked by the peptidomimetic inhibitor $\gamma$-secretase inhibitor II (De Strooper et al., 1999; Wolfe et al., 1999). We use the nomenclature for NOTCH1 processing and products defined by Mumm et al. (2000) and Brou et al (2000). Therefore, processing of NOTCH1 by a furin-like convertase at the S1 site produces NOTCH1-PF1 (Logeat et al., 1998), ligand-dependent processing at the S2 site by TACE produces NOTCH1-PF2, and ligand-dependent processing at the S3 site by a presenilin-mediated cleavage produces the active intracellular portion of NOTCH1 or NOTCH1-PF3 (De Strooper et al., 1999). Inhibition of $\gamma$-secretase should result in the accumulation of NOTCH1-PF2 if the inhibitor is effective (Brou et al., 2000; Mumm et al., 2000). Therefore, we tested the effectiveness of $\gamma$-secretase inhibitor II in preventing the production of NOTCH1-PF3 by assaying for the accumulation of NOTCH1PF2 (which is expected because NOTCH-PF2 is the precursor for NOTCH1-PF3) and for the decrease in NOTCH1-PF3 in EGFgenerated neurospheres. Western blot analysis of P1 neurospheres treated for $4 \mathrm{hr}$ with $\gamma$-secretase inhibitor II $(50 \mu \mathrm{M})$ consistently revealed the appearance of a band (NOTCH1-PF2; $n=4$ ) below that of NOTCH1-PF1, compared with EGF and $\mathrm{EGF}+\mathrm{DMSO}$ controls, suggesting that the inhibitor was preventing the production of NOTCH1-PF3 (Fig. 2A). Furthermore, nuclear protein extracts of $\mathrm{P} 1$ neurospheres that were treated for $4 \mathrm{hr}$ with $\gamma$-secretase inhibitor II revealed a decrease (relative to HISTONE H1 expression: $-34 \%$ in experiment $1,-27 \%$ in experiment 2) in NOTCH1-PF3 compared with DMSO controls, confirming that the inhibitor was preventing the production of NOTCH1-PF3 (Fig. 2B). Addition of $\gamma$-secretase inhibitor $(30-50 \mu \mathrm{M})$, at plating, to a single-cell suspension derived from primary neurospheres, delayed the formation of $\mathrm{P} 1$ neurospheres by $\sim 24 \mathrm{hr}$, compared with vehicle controls (Fig. $2 \mathrm{C}-\mathrm{H}$ ). Once generated, inhibitor-treated $\mathrm{P} 1$ neurospheres appeared more differentiated, compared with vehicle controls (Fig. 2, compare $G$, $H$ ). Western blot analysis revealed that $24 \mathrm{hr}$ after inhibitor addition, NOTCH1-PF1 protein expression was reduced to $52 \%$ of vehicle-treated sister cultures $(n=3, p<0.005)$ (Fig. $2 I)$, suggesting that inhibition of NOTCH1 activation leads to an overall decrease in NOTCH1 production. After 3 DIV, $\gamma$-secretase inhibitor- and vehicle-treated P1 neurospheres of 150-200 $\mu \mathrm{m}$ in diameter were isolated, dissociated, and examined for the formation of P2 neurospheres. $\gamma$-secretase inhibitor treatment reduced P2 neurosphere formation to $61 \%$ of control $(n=3, p<$ 0.05 ) (Fig. 2I). These results suggest that, in addition to expres-

$\leftarrow$

presence of $\gamma$-secretase inhibitor II (30 $\mu \mathrm{M})$ compared with DMSO controls $\left(^{*} p<0.05\right.$; $t$ test $n=3)$. Inset shows a reduction of NOTCH1-PF1 expression in P1 neurospheres treated for 1 DIV, from the time of plating, with $50 \mu \mathrm{m} \gamma$-secretase inhibitor II compared with the DMSO control $(p<0.05 ; t$ test; $n=3)$, indicating that constitutive inhibition of NOTCH1 activation for at least $24 \mathrm{hr}$ leads to an overall decrease in NOTCH1 expression. Scale bar, $100 \mu \mathrm{m}$. N.S., Nonspecific; $\gamma$-SI, $\gamma$-secretase inhibitor. 
sion levels, NOTCH1 cleavage and signaling regulate the maintenance of EGFresponsive NSCs.

\section{Signaling through CNTFR $\alpha$ regulates expression of Notch1 in vitro}

Given the similarity between the actions of NOTCH1 and gp130-mediated signaling on NSC maintenance, we asked whether gp130-mediated signaling, stimulated by CNTF, could regulate NOTCH1 expression in EGF-responsive NSCs. We first explored whether CNTFR $\alpha$ and NOTCH 1 are coexpressed in the developing E14 basal forebrain, the origin of embryonic EGF-responsive NSCs. We found that most of the NOTCH1-expressing cells coexpress CNTFR $\alpha$ in the E14 basal forebrain germinal zone (Fig. $3 A-D$ ), consistent with the hypothesis of a link between CNTFR $\alpha$ and NOTCH1 signaling in forebrain NSCs. We then examined the results of gp 130 activation on NOTCH1 signaling in EGF-generated neurospheres. When screening, using RTPCR, for Notch gene expression, we found that P1 neurospheres expressed Notch 1 and Notch 3 but not Notch 2 or Notch4 (data not shown). Quantitative RT-PCR Southern blot analysis was used to examine Notch expression in P1 neurospheres generated in EGF + CNTF $(20 \mathrm{ng} / \mathrm{ml})$ compared with those generated in EGF. Notch1 increased approximately threefold in 1 DIV EGF+CNTFgenerated $\mathrm{P} 1$ neurospheres compared with EGF-generated P1 neurospheres (Fig. 3E), whereas Notch3 expression was unaffected (Fig. 3F). Because increases in mRNA expression are not always followed by concomitant increases in protein expression, we sought definitive evidence that gp130-mediated signaling could regulate NOTCH1 expression. We used two antibodies to NOTCH1 to ensure that we were in fact measuring bona fide NOTCH1 protein. Figure $3 G$ shows that in a Western blot, both the 93-4 (Shawber et al., 1996) and Santa Cruz M-20 antibodies identify increases in NOTCH1-PF1 and NOTCH1-PF2 (more than fivefold; $p<$ $0.01 ; n=5)$ in 3 DIV EGF+CNTFgenerated $\mathrm{P} 1$ neurospheres compared with EGF-generated P1 neurospheres. Furthermore, nuclear protein extracts of 3 DIV EGF+CNTF-treated P1 neurospheres demonstrate an increase in NOTCH1-PF3 compared with EGF controls as determined by Western blot analysis (Fig. $3 H)(p<0.01 ; t$ test; $n=$ 4). Together, these findings suggest that
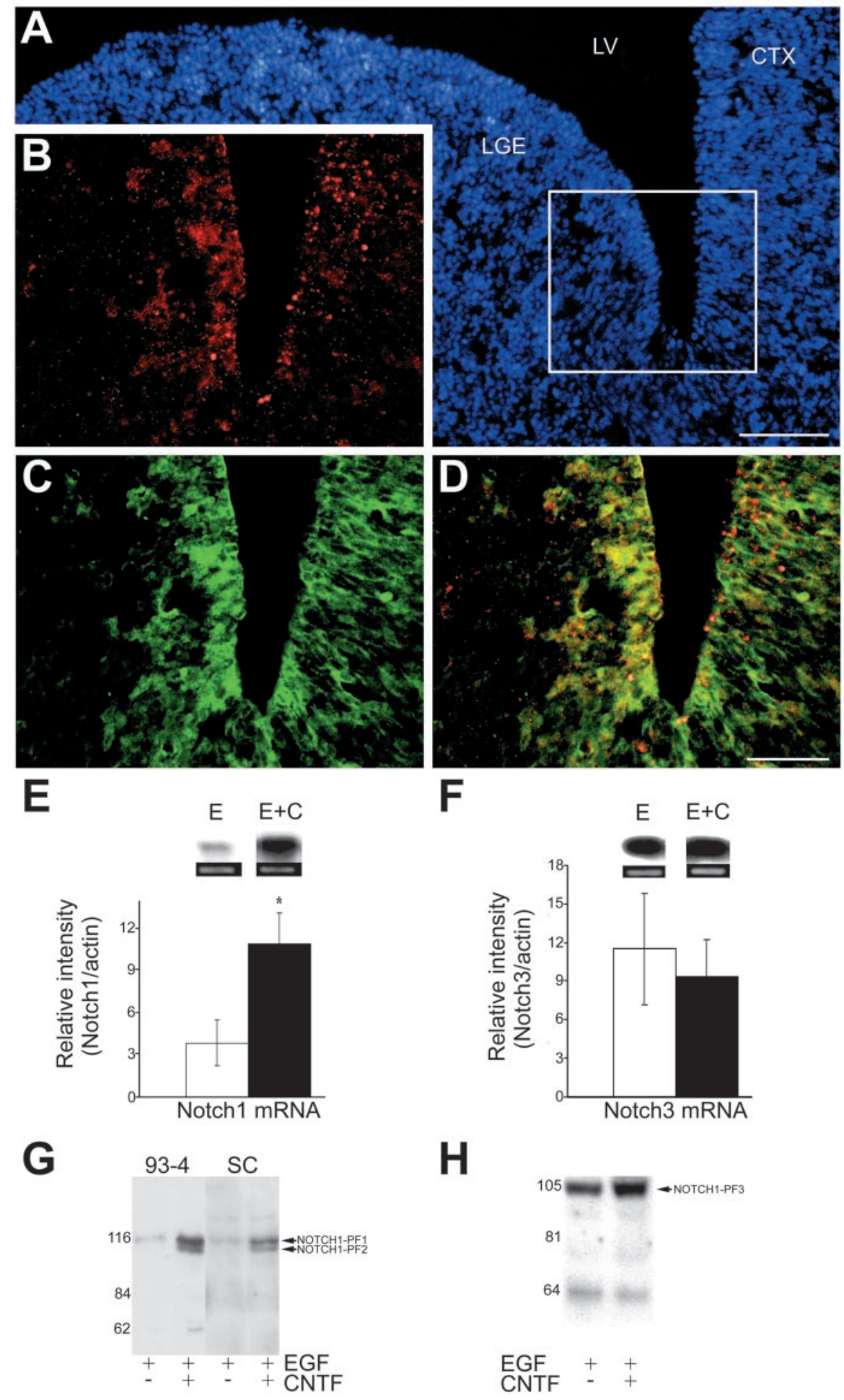

Figure 3. EGF + CNTF treatment of embryonic P1 neurospheres specifically increases Notch1 mRNA and protein expression. $A-D$, Immunofluorescence micrographs of a coronal section $(8 \mu \mathrm{m})$ through the forebrain of an $\mathrm{E} 14$ mouse embry 0 . $A$, Nuclei were labeled with Hoechst 33258 (blue). CNTFR $\alpha$-immunoreactive cells in the ventricular zone were visualized with Cy3 ( $B$, red), and Notch1-immunoreactive cells were labeled with FITC $(C$, green). D, A merged image of $B$ and $C$, where yellow staining indicates colocalization of NOTCH1 and CNTFR $\alpha$. Box in $A$ indicates area magnified in B-D. E-G, NSCs were cultured in $20 \mathrm{ng} / \mathrm{ml}$ EGF, the absence or presence of $20 \mathrm{ng} / \mathrm{ml} \mathrm{CNTF}$, and harvested after $24 \mathrm{hr}$ for total RNA and RT-PCR Southern blot analysis $(E, F)$, or after 3 DIV for Western blot analysis ( $G$. Notch1 expression increased significantly $\left({ }^{*} p<0.05\right.$ vs EGF; $t$ test; $n=3$ ) after 1 DIV of CNTF treatment $(E)$ compared with no change in Notch3 expression $(F)$. Both the 93-4 and Santa Cruz intracellular N0TCH1 antibodies reveal an increase in NOTCH1-PF1 and NOTCH1-PF2 proteolytic products after 3 DIV of EGF+CNTF treatment compared with EGF alone $(G)(p<0.01 ; t$ test; $n=5)$. Nuclear expression of NOTCH1-PF3 increases in 3 DIV P1 neurospheres cultured constitutively in EGF+CNTF compared with EGF alone $(H)(p<0.01 ; t$ test; $n=4)$. Scale bars: $A, 50 \mu \mathrm{m} ; D, 100 \mu \mathrm{m}$. $L G E$, Lateral ganglionic eminence; $L V$, lateral ventricle; $C T X$, cortex. 
A

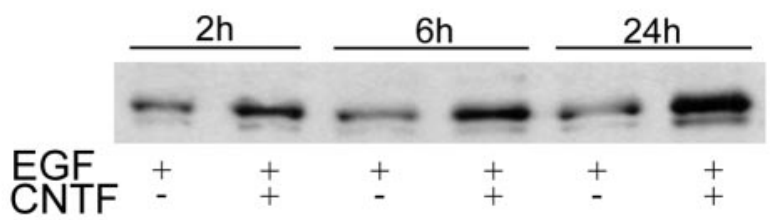

B

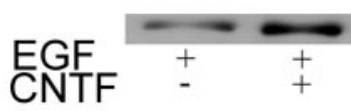

C

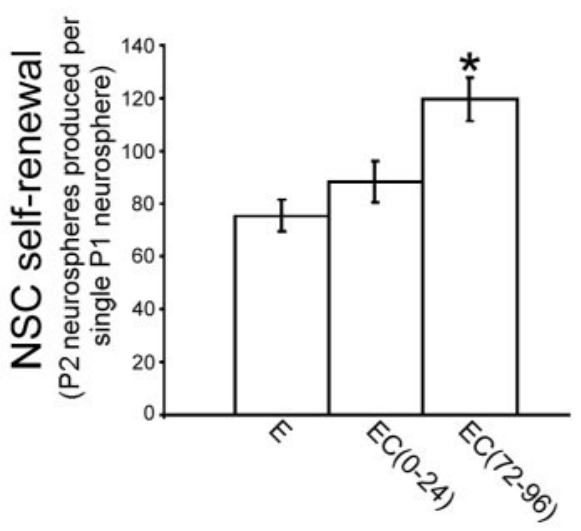

Figure 4. Cell-cell contact is not required for CNTF to increase NOTCH1 expression but is required for CNTF to increase NSC self-renewal. $A$, Western blot analysis reveals that NOTCH1PF1 expression increases as early as $2 \mathrm{hr}$ after CNTF treatment of 3 DIV EGF-derived P1 neurospheres $(n=3)$. B, Totally dissociated primary neurospheres were cultured in EGF+CNTF for 6 hr; Western blot analysis demonstrates a threefold increase in NOTCH1-PF1 expression ( $p<$ $0.05 ; t$ test; $n=3$ ) compared with EGF controls. No increase in NOTCH1-PF2 could be detected. C, P1 neurospheres were generated in EGF or in EGF + CNTF in the absence $(0-24 \mathrm{hr})$ or presence (72-96 hr) of cell-cell contact. After 7 DIV the three different groups were assayed for the formation of P2 neurospheres by single-sphere dissociation and culture in EGF alone (each group was washed at 24 and $96 \mathrm{hr}$ ). Compared with EGF, addition of (NTF for $24 \mathrm{hr}$ at 3 DIV increased the formation of P2 neurospheres by $59 \%$ ( $p<0.0001$; Tukey HSD test; $n=3$ ), whereas there was no difference in $\mathrm{P} 2$ neurosphere formation when CNTF was added for the first $24 \mathrm{hr}(p>0.58$; Tukey HSD test; $n=3$ ).

the increase in NOTCH1 synthesis in CNTF-stimulated P1 neurospheres further results in ligand-mediated activation of NOTCH1 signaling.

\section{Lateral inhibition is not necessary for CNTF to increase NOTCH1 expression; however, cell-cell contact is required for CNTF to increase NSC self-renewal}

To determine whether CNTF increases Notch1 expression directly or indirectly, we examined the time course of CNTFinduced NOTCH1 expression. NOTCH1 expression increases significantly in 3 DIV neurospheres after as little as $2 \mathrm{hr}$ of exposure to CNTF (Fig. 4A). These data suggest that de novo synthesis of another protein, which would then act to increase expression of NOTCH1, is unlikely. In all of the above mentioned experiments, we examined Notch 1 mRNA and protein expression in developing clusters of cells (neurospheres). Given the cell-cell contact within neurospheres, it is possible that lateral inhibition mediates the actions of CNTF on Notch1 expression. In this case, CNTF could decrease ligand expression, which through lateral inhibition would increase Notch1 expression in the same popu- lation of cells. To examine this possibility, we tested whether $6 \mathrm{hr}$ of EGF+CNTF exposure $(20 \mathrm{ng} / \mathrm{ml})$, in comparison with EGF alone, could increase NOTCH1-PF1 or NOTCH1-PF2 expression in a completely dissociated single-cell suspension $\left(5 \times 10^{4}\right.$ cells/ml) derived from $7 \mathrm{DIV}$ primary neurospheres. Western blot analysis shows that in the absence of cell-cell contact, CNTF can increase NOTCH1-PF1 expression (more than threefold; $p<$ 0.05; $t$ test; $n=3$ ) (Fig. $4 B$ ). We did not detect NOTCH1-PF2 in either condition, which is what we would have predicted considering that this band should appear only in the presence of ligandmediated activation of TACE and further indicates that we have correctly identified NOTCH1-PF2. These data suggest that the CNTF-induced increase in NOTCH1 expression is ligand independent but that NOTCH1 activation requires ligand mediated cleavage.

We then tested whether an increase in NOTCH1 expression, without its activation, was sufficient to increase the production of P2 neurospheres. Thus we treated P1 cells with EGF alone or with EGF and then added CNTF for $24 \mathrm{hr}$ at plating or for $24 \mathrm{hr}$ at 3 DIV. All conditions were washed at 1 and 4 DIV. After 7 DIV, we dissociated single P1 neurospheres to assay for self-renewal (by counting the numbers of $\mathrm{P} 2$ neurospheres per single $\mathrm{P} 1$ neurosphere). Figure $4 C$ shows that there was no significant increase in self-renewal of P1 neurospheres that were treated with CNTF for the first $24 \mathrm{hr}$, whereas there was a significant increase in selfrenewal capacity in the $\mathrm{P} 1$ neurospheres treated with CNTF at 3 DIV $[p<0.0001$; Tukey honestly significant difference (HSD) test; $n=3$ ]. These data suggest that cell-cell contact, which is present in 3 DIV spheres and almost entirely absent in plated cells (for the first $24 \mathrm{hr}$ at this concentration), is necessary for CNTF to increase the self-renewal capacity of NSCs.

Although we had shown that CNTF could increase NOTCH1 expression in EGF-generated neurospheres, we had yet to demonstrate directly the phenomenon at the single-cell level. With this in mind and to determine whether CNTF increases expression of NOTCH1 in all EGF-generated cells or rather increases the number of NOTCH1-expressing cells, we examined the expression of NOTCH1 in dissociated primary spheres (P1 cells) treated for $6 \mathrm{hr}$ with either EGF or EGF+CNTF. We observed that all of the cells, in either condition, expressed some level of immunoreactivity to NOTCH1 (data not shown). We found, however, that addition of CNTF to the culture increased the number of cells that labeled intensely (Fig. 5, arrowheads) (see Materials and Methods for experimental details) compared with those that labeled weakly (Fig. 5, small arrows) for NOTCH1 by $49 \%(p<0.003 ; t$ test; $n=3$ ) compared with EGF alone. Taken together, these findings suggest that CNTF directly upregulates NOTCH1 expression in EGF-generated NSC progeny.

\section{NOTCH1 expression correlates with the capacity of P1} neurospheres to generate P2 neurospheres in LIFR $\beta$ knockout mice

We have recently reported that adult LIFR $\beta$ heterozygotes show a decrease in the ability to produce forebrain neurospheres (indicative of NSC number), compared with their wild-type littermates (Shimazaki et al., 2001). To determine whether gp130 regulation of NOTCH1 function is associated with changes in NSC selfrenewal, we compared NOTCH1 protein expression, using Western blot analysis, in 3 DIV LIFR $\beta^{+/+}$and $L I F R \beta^{-/-}$embryonic P1 neurospheres treated with EGF or EGF + CNTF. Furthermore, we examined the capacity of wild-type and mutant P1 neurospheres to produce P2 neurospheres by single sphere dissociation. In wild-type $(+/+)$ P1 neurospheres, both NOTCH1-PF1 
and -P2 neurosphere production increase after CNTF addition, whereas no increase in NOTCH1-PF1 or -P2 neurosphere production was observed in LIFR $\beta^{-/-} \mathrm{P} 1$ neurospheres cultured in EGF+CNTF (Fig. 6). Glycoprotein 130 signaling through IL6R does not require LIFR $\beta$ and thus provides a means to test whether gp130 activation is sufficient for increasing NOTCH1-PF1 expression and P2 neurosphere production. Because the IL6 receptor is not expressed in EGFgenerated neurospheres (T. Shimazaki and S. Weiss, unpublished observations), we generated $L I F R \beta^{-/-} \mathrm{P} 1$ neurospheres in the presence of sIL6R+IL6. Activation of gp130 signaling in $L I F R \beta^{-/-} \mathrm{P} 1$ neurospheres with sIL6R + IL6 was sufficient to increase their expression of NOTCH1-PF1 and -P2 neurosphere production (Fig. 6). These experiments suggest that activation of gp130 signaling is the common element in CNTFR-, LIFR $\beta$ - and IL6R-mediated increases in NOTCH1 expression of P1 neurospheres and $\mathrm{P} 2$ neurosphere production.

\section{The CNTF-induced increase in NOTCH1 expression is context dependent}

In vitro, one can determine the effects of factors on a population of cells one at a time or in combination. This is certainly not the case in the developing germinal zone, where progenitor cells are likely exposed to several factors at the same time. Thus, we sought to determine whether CNTF could increase NOTCH1-PF1 expression in the absence of EGF. We stimulated dissociated 7 DIV primary neurospheres $\left(5 \times 10^{4}\right.$ cells/ml $)$ with CNTF for $6 \mathrm{hr}$, in the absence or presence of EGF (Fig. 7A). In the absence of EGF, CNTF failed to increase NOTCH1-PF1 expression. These data suggested that only cells receiving an EGF signal could respond to CNTF with an increase in NOTCH1 expression. An alternative possibility is that a proliferative state is necessary for CNTF to increase NOTCH1 expression in NSCs. Thus, we tested whether CNTF could increase NOTCH1-PF1 expression in the absence of EGF but in the presence of FGF2, another principal NSC mitogen. Figure $7 B$ demonstrates a significant increase in NOTCH1-PF1 expression in a singlecell suspension derived from 7 DIV primary neurospheres cultured for $24 \mathrm{hr}$ in FGF2+CNTF, compared with those exposed to FGF2 alone. Therefore, induction of NOTCH1 expression by CNTF appears to require that NSCs be in a proliferative state.

\section{CNTF can upregulate NOTCH1 expression in vivo}

Intraventricular infusion of EGF + CNTF resulted in a $50 \%$ increase in the number of neurospheres that could be derived from the periventricular area of the adult brain, compared with EGF infusion alone (Shimazaki et al., 2001). Given that CNTF could
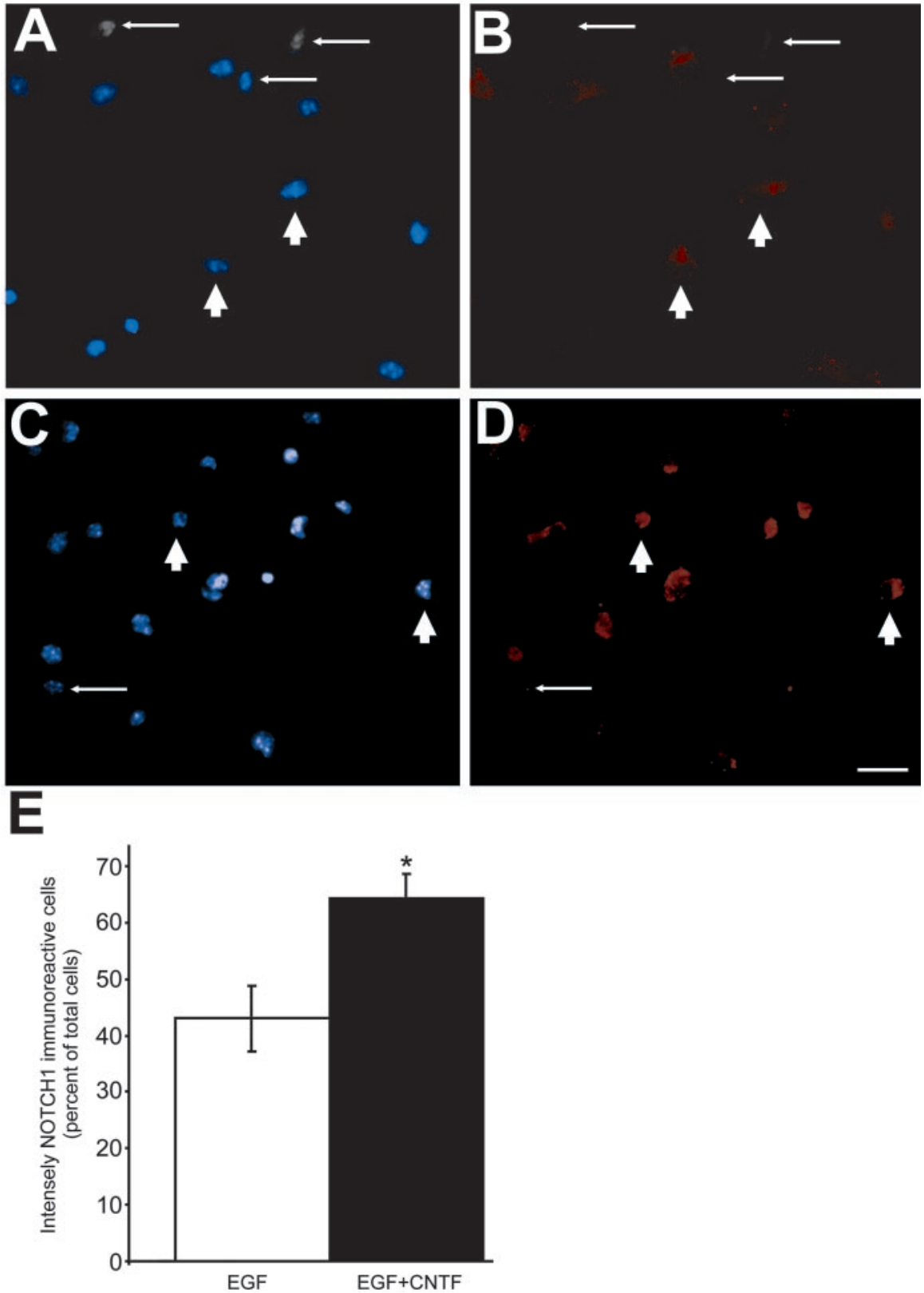

Figure 5. CNTF increases the number of intensely NOTCH1-immunoreactive cells. Primary neurospheres were dissociated and en cultured on poly---ornithine-coated coverslips for $6 \mathrm{hr}$ in either EGF $(A, B)$ or EGF + CNTF $(C, D)$, and blind counts were made Hoechst 33258 (blue). NOTCH1-immunoreactive cells were labeled with rhodamine $(B, D, r e d)$. $E$, Compared with cells immunoreactive cells ( ${ }^{*} p<0.003 ; t$ test; $n=3$ ). Arrowheads indicate examples of cells that stain intensely for NOTCH1, and small arrows indicate examples of cells that stain weakly for NOTCH1. Scale bar, $20 \mu \mathrm{m}$.

only induce the expression of NOTCH1 in the presence of either EGF or FGF2 (Fig. 7), we compared NOTCH1 expression in the forebrain periventricular area of EGF- versus EGF+CNTFinfused adult mice. Adult CD1 mice were infused with EGF or $\mathrm{EGF}+\mathrm{CNTF}$ for $6 \mathrm{~d}$, and the brains were processed for NOTCH1 immunohistochemistry ( $n=3$ for each treatment). The lateral aspect of the periventricular area (the specific region that is thought to be enriched in NSCs) of brains infused with EGF + CNTF exhibited a much thicker and more intense area of NOTCH1 expression compared with animals infused with EGF alone (Fig. 8, compare $A, B$ ). In particular, although NOTCH1 

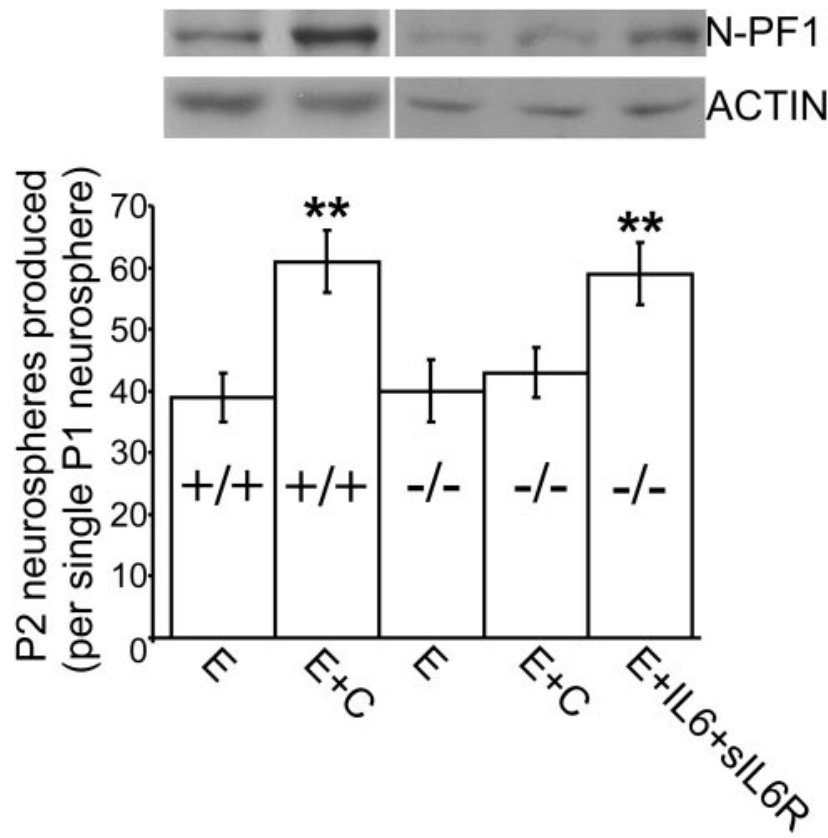

Figure 6. $\quad \| 6+s \mid L 6 R$ increases NOTCH1 expression and P2 neurosphere production in P1 neurospheres generated from $L I F R \beta^{-/-}$mice. P1 neurospheres were generated from wildtype $(+/+)$ or null mutant $(-/-)$ LIFR $\beta$ littermates, in the various conditions indicated, and were then assayed after 3 DIV for NOTCH1 protein with Western blot and after 7 DIV for P2 neurosphere production by single-sphere dissociation in EGF alone. Increase in $\mathrm{P} 2$ neurosphere production in wild-type $(+/+) \mathrm{EGF}+$ CNTF generated P1 neurospheres and in LIFR $\beta^{-/-} \mathrm{P1}$ neurospheres generated in EGF + IL6 + sll6R correlated with concomitant increases in NOTCH1PF1 expression (inset). CNTF had no effect on P2 neurosphere production or NOTCH1-PF1 expression in $L I F R \beta^{-/-} \mathrm{P} 1$ neurospheres. ${ }^{* *} p<0.01$ versus $+/+$ control culture or $-/-$ control culture; Tukey HSD test; $n=5$. N-PF1, NOTCH1-PF1.

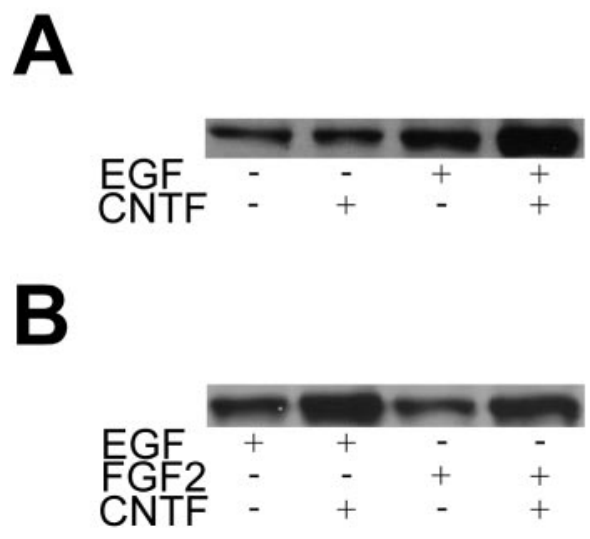

Figure 7. The CNTF-induced increase in NOTCH1 expression in dissociated primary neurospheres is dependent on either EGF or FGF2 signaling. $A, B$, Single-cell suspensions derived from primary neurospheres and cultured for $6 \mathrm{hr}$ in the indicated conditions reveal that CNTF had no effect on NOTCH1-PF1 expression in the absence of EGF $(B)(n=3)$ and that CNTF can increase NOTCH1-PF1 expression in either EGF- or FGF2-containing media (B) $(p<0.05 ; t$ test; $n=3)$.

immunoreactivity is sporadic on the lateral aspect of the ventricle in the EGF infused brain, NOTCH1 staining appears as a thick, continuous layer in the EGF+CNTF-infused brain (Fig. 8, compare $C, E$ ). We then performed double-blind counts on the number of cells immunoreactive for NOTCH1 in the EGFand EGF+CNTF-infused animals. Of the cells within theexpanded lateral ventricular area, $76 \pm 12 \%$ expressed NOTCH1 in animals infused with EGF+CNTF compared with $39 \pm 7 \%$ in the EGF-infused animals $(p<0.026 ; n=3$ each group; $t$ test). Thus, CNTF, in the presence of EGF, can upregulate the number of NOTCH1-immunoreactive cells in vivo.

\section{CNTF stimulation changes mRNA and protein expression levels of genes known to be involved in the Notch1 signaling pathway}

The bHLH genes Hes 1 and Hes5 are known mediators of Notch signaling (Kageyama and Ohtsuka, 1999) and may be involved in NSC or progenitor cell maintenance (Nakamura et al., 2000, Ohtsuka et al., 2001). In addition, HES1 can directly downregulate Mash1 expression, a gene whose expression is an initial step in the NSC to progenitor cell transition (Chen et al., 1997; Torii et al., 1999). We thus expected that gp130mediated signaling, initiated by CNTF, would increase the expression of Hes 1 and Hes5, with a concomitant decrease in Mash1 expression. Surprisingly, 3 DIV P1 neurospheres generated in EGF + CNTF appeared to show a downregulation in Hes 1 expression, although this did not achieve statistical significance (Fig. 9A) $(p>0.05 ; n=3)$. Hes5 expression was significantly reduced in 3 DIV EGF + CNTF P1 neurospheres compared with the equivalent neurospheres generated in EGF alone (Fig. 9A) $(p<0.05 ; n=3)$. We also confirmed that there were no transient increases in Hes 1 or Hes 5 expression at 2 or $6 \mathrm{hr}$ after plating in EGF $+\mathrm{CNTF}$ compared with EGF alone (data not shown). However, as expected, CNTF markedly decreased Mash 1 expression in 3 DIV EGF+CNTF P1 neurospheres compared with EGF controls (Fig. 9B) $(p<$ $0.05 ; n=3$ ). MASH1 has been reported to downregulate its own mRNA expression (Meredith and Johnson, 2000); therefore we examined MASH1 protein expression after CNTF treatment. We found that CNTF treatment significantly decreases MASH1 expression in 3 DIV neurospheres (Fig. 9B) $(p<0.05 ; n=3)$.

Given the decrease in MASH1 expression and because it is a known transcriptional activator of Notch ligand expression (Casarosa et al., 1999), we examined Delta/Serrate gene expression in EGF-generated neurospheres. RT-PCR analysis revealed that Delta 1 and -3 and Jagged 1 and -2 were expressed in EGF-generated P1 neurospheres (data not shown). Furthermore, we found that the expression of Delta3 decreased (Fig. 9C) $(p<0.05, n=3)$ in 3 DIV P1 neurospheres cultured in $\mathrm{EGF}+\mathrm{CNTF}$, compared with EGF alone. The decrease in Delta3 expression is consistent with the observed decrease in Mash $1 \mathrm{mRNA}$ and protein expression in EGF $+\mathrm{CNTF}$-treated P1 neurospheres and with our observation that EGF + CNTF treatment of $\mathrm{P} 1$ neurospheres increases Notch1 expression.

\section{Discussion}

This report demonstrates, for the first time, a link between gp130 and NOTCH1 signaling pathways in the regulation of NSC maintenance. Our results show a requirement for NOTCH1 signaling in the maintenance and generation of NSCs. We find that gp130 signaling specifically increases NOTCH1 expression in EGF-responsive NSCs in vitro and in vivo. Furthermore, we find that the increase in NOTCH1 expression is followed by an increase in the ligand-mediated cleavage of NOTCH1-PF1 into NOTCH1-PF2 and further into NOTCH1-PF3. Our observed decreases in Mash1 and Delta3 are consistent with activation of gp130 leading to an increase in NOTCH1 signaling. However, our results and a 
careful reading of related studies (see below) suggest that Hes 1 and Hes 5 may not be the critical components of NOTCH1 signaling that are involved in NSC maintenance.

\section{Glycoprotein 130 activation regulates NOTCH1signaling, which is required for the maintenance ofEGF-responsive NSCs}

Recent evidence suggests that the phenotypic response to Notch signaling in developing forebrain precursors is variable and dependent on temporal and spatial cues (Chambers et al., 2001). Moreover, it appears that Notch signaling is unable to regulate the maintenance of neural crest stem cells (Morrison et al., 2000). Therefore, we first tested whether NOTCH1 expression and signaling play a role in EGF-responsive NSC maintenance. Antisense to Notch1 reduced its expression and consistently decreased secondary neurosphere production. Furthermore, culture of neurospheres in the presence of a $\gamma$-secretase inhibitor, known to reduce production of activated NOTCH1 (De Strooper et al., 1999), also reduced the production of secondary neurospheres (Fig. $2 I$ ). Our results concur with the observations of Hitoshi and colleagues (2002), implicating NOTCH1 signaling in the maintenance of EGF-responsive NSCs. However, in contrast to their findings, we demonstrate that blocking the processing of NOTCH1PF2 to NOTCH1-PF3, using a $\gamma$-secretase inhibitor, also inhibited NSCs from proliferating in response to EGF. This suggests that NOTCH1 activation is required for expansion and generation of EGF-responsive NSCs. Similarly, FGFs require an intact Notch signaling pathway to prevent the differentiation of E10.5 neuroepithelial progenitors cells into neurons (Faux et al., 2001). The conclusion by Hitoshi et al. (2002) that Notch signaling is not required for the generation of NSCs is based on their observation that $R B P-J \kappa^{-/-}$ ES cells could give rise to the proliferation of primitive NSCs. However, the lineage relationship between these ES cell-derived NSCs and in vivo generated NSCs is unclear, as is the role of ES cell-derived NSCs in neurogenesis. Indeed, the fact that NSCs could not be isolatedfrom $R B P-J \kappa^{-/-}$or presenilin $1^{-/-} /$presenilin $2^{+/-}$embryos concurs with our data that Notch signaling is required for the generation of NSCs.

We then tested the hypothesis that gp130-mediated signaling regulates NOTCH1 signaling in NSCs. Our results demonstrate that CNTF specifically induces Notch $1 \mathrm{mRNA}$ and protein expression (no change in Notch3 expression) in NSCs. With regards to Notch1, our data are consistent with that of Faux et al. (2001), who reported that LIF and members of the TGF $\beta$ family could increase the expression of Notch1 in E10.5 neuroepithelial progenitor cells, but inconsistent in the regulation of Notch3, which was also upregulated by LIF and other factors in their system. Although some of these discrepancies may be attributable to the tissue or ontogenetic origin of the precursors, Faux and colleagues (2001) did not explore how growth factors regulated Notch1 signaling or its relevance to NSC function. In vivo, we found that CNTF, in the presence of EGF, upregulates the number of NOTCH1-expressing cells [as we reported, it increases NSC numbers (Shimazaki et al., 2001)] in the adult forebrain periventricular area, which is the location of adult NSCs. The ability of sIL6R+IL6 to enhance NOTCH1 and NSC numbers in LIFR $\beta^{-/-}$neurospheres demonstrates that gp130 activation mediates the increases in NOTCH1 expression and NSC maintenance. These data concur with the recent findings of Hatta et al. (2002) that signaling by gp130 keeps embryonic precursors in the stem cell state and suggests that this effect may be mediated by NOTCH1.

The observations that CNTF enhances NOTCH1-PF1 expression rapidly and in the absence of cell-cell contact suggests a direct action on NSCs that does not involve lateral inhibition. This further suggests that the decrease of Delta3 that we observed is a result and not a cause of increased NOTCH1 signaling. On the other hand, we demonstrate that cell-cell contact is required for CNTF to increase NOTCH1-PF2 and NSC selfrenewal (Fig. $4 B, C$ ).

EGF and gp130 signaling pathways cooperatively regulate NOTCH1 signaling in NSCs and may establish the pattern of cell contact-mediated signaling during development

The results of this study suggest that the gp 130-mediated increase in NOTCH1 signaling is context dependent. CNTF only induced an increase in NOTCH1 expression in the presence of either EGF or FGF2. Figures $4 A-F$ and $7 B$ demonstrate that EGF alone can 

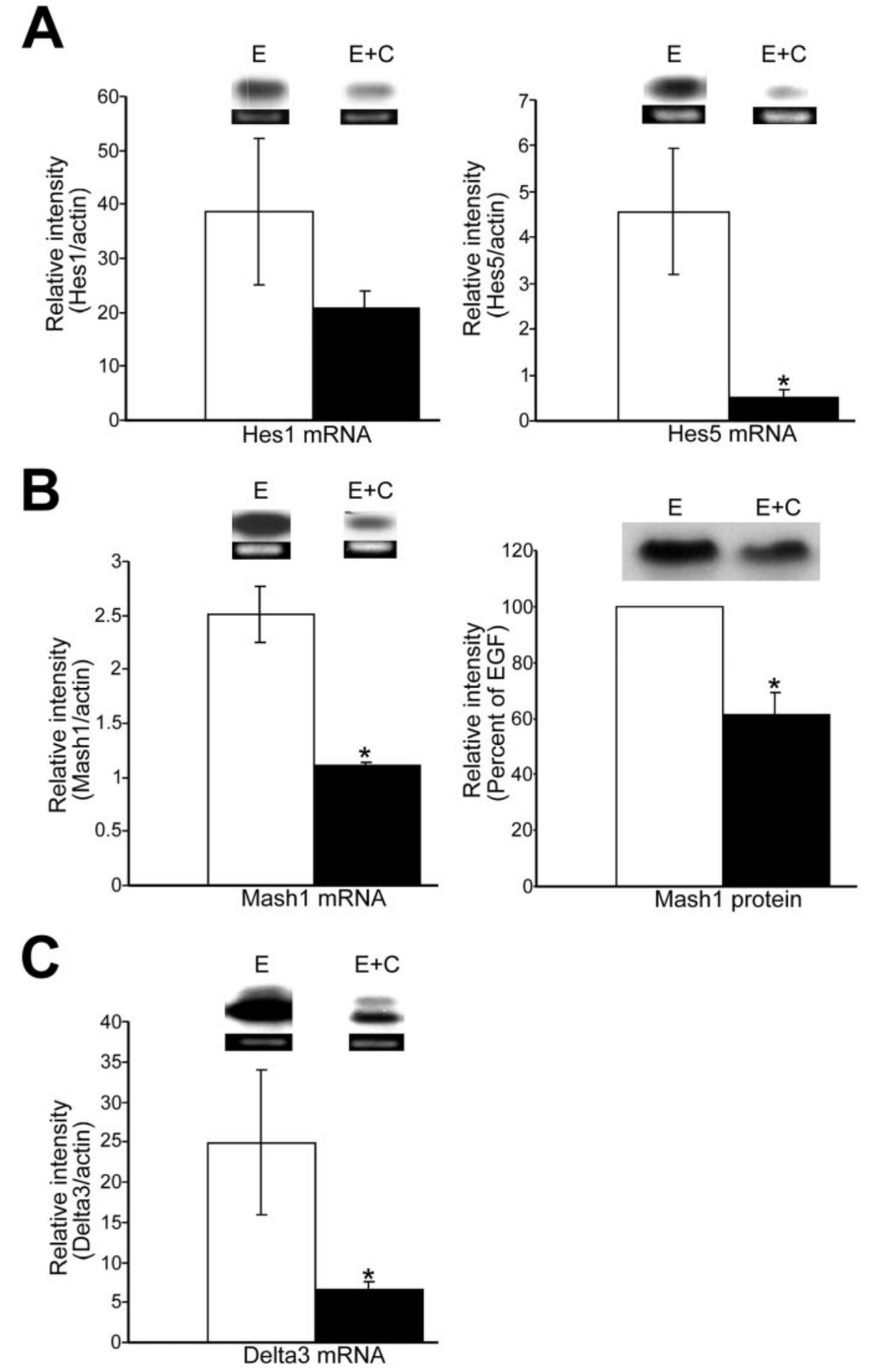

Figure 9. CNTF treatment changes the expression of genes regulated by NOTCH1 signaling. $A-C$, Primary neurospheres derived from the E14 striatum were grown in the presence of EGF for $7 \mathrm{DIV}$, dissociated, and then cultured $\left(5 \times 10^{4} \mathrm{celll} / \mathrm{ml}\right)$ in either EGF or EGF + CNTF. The cells were then harvested for total RNA or protein at 3 DIV and processed for RT-PCR Southern or Western blot analyses as described in Materials and Methods. A, Constitutive CNTF treatment significantly decreases Hes 5 expression, whereas Hes 1 expression in CNTF-treated P1 neurospheres does not differ significantly from 3 DIV EGF-derived P1 neurospheres. B, Mash1 expression, $\mathrm{mRNA}$, and protein are significantly reduced in P1 neurospheres cultured for 3 DIV in the presence of EGF+CNTF compared with EGF alone. C, Delta3 expression is reduced in 3 DIV EGF + CNTF P1 neurosphere cultures compared with EGF cultures. ${ }^{*} p<0.05$ versus EGF; $t$ test $(A-C ; n=3)$.

increase NOTCH1 expression in vitro. Both EGF and CNTF can phosphorylate tyrosine residues on STAT3, which is necessary for the dimerization of STAT3 and its translocation to the nucleus (for review, see Akira, 1999; Turnley and Bartlett, 2000). Additionally, it has been reported that MAP kinase can phosphorylate dimerized STAT proteins on serine residues, which appears to be necessary for STAT-dependent transcriptional activation (Akira, 1999). Although the upstream 5' sequence of mouse Notch 1 is unavailable to us, we examined the genomic sequence upstream of Drosophila Notch for the presence of STAT binding sites. The existence of two putative STAT-element binding sites, $5^{\prime}$ TTCNNNGAA in Drosophila (Kwon et al., 2000) at $-954:-962$ and $-1035:-1043$ with respect to the Notch start codon (designated as 0 ), is highly suggestive that gp130mediated JAK/STAT signaling may directly regulate the transcription of Notch1 in Drosophila and in the mouse. Thus, it is plausible that EGF and CNTF signaling may cooperatively activate the dimerization, translocation, and activation of STAT3 proteins, which may in turn act to promote Notch1 expression.

EGF- and gp130-mediated signaling may also cooperate to establish the pattern of NOTCH1 signaling within the developing CNS. For example, cells within the ventricular zone, exposed to high levels of CNTF/LIF and EGF signaling, would express high levels of NOTCH1 and through lateral inhibition "determine" how cell-cell contact-mediated signaling would allow distinction/separation of the adjacent progenitor cell pool in the subventricular/ mantle zones. Thus cells further removed from EGF/CNTF would become progenitor cells, limited in their capacity to self-renew and more able to express genes, such as Mash1, involved in the determination of restricted neural progenitor cells. Indeed, EGF+ CNTF decreased Mash 1 mRNA and protein expression in NSC cultures, as this model would predict. A similar concept was suggested previously by Price et al. (1997), with respect to Notch and EGFR signaling in the establishment or maintenance of posterior follicle cell fates in Drosophila. They provide evidence suggesting that EGFR signaling influences NOTCH signaling in posterior follicle cells and the establishment of the expression levels of DELTA ligand, which would, in turn, be maintained by lateral inhibition. Thus, as reported in other systems, our results support the contention that cell contact-mediated signaling and non-cell contact-mediated epigenetic signaling pathways are intimately linked in the establishment of neural patterning and development.

\section{Mediation of NSC maintenance and proliferation by} NOTCH1 signaling may be independent of Hes1 and Hes5

In this study, we found that neurospheres cultured for 3 DIV in EGF + CNTF demonstrate a fivefold increase in NOTCH1 expression compared with EGF controls. This increase in NOTCH1 ex- 
pression is concomitant with a significant decrease in Hes5 expression and a trend toward a decrease (did not achieve statistical significance) in Hes1 expression. Given the decrease in the progenitor determination gene Mash1 (Fig. 9B), a gene whose transcription is repressed by Hes1 (Chen et al., 1997), it is surprising that there was no increase in Hes gene expression in the CNTF treated-cultures. However, these observations are not unlike those made by Shawber et al. (1996) whereby NOTCH1 activation by JAGGED1, which kept $\mathrm{C} 2 \mathrm{C} 12$ myoblasts from differentiating, did not result in the upregulation of Hes1. Stable transfection of C2C12 myoblasts with Hes 1 was also unable to inhibit their differentiation. Additionally, Furukawa et al. (2000) reported that overexpression of activated Notch1 in the retina increased clone size, whereas overexpression of Hes 1 did not. Finally, there was no decrease found in the expression of Hes1 in presenilin $1^{-/-}$brains (Handler et al., 2000) or in $R B P-J \kappa^{-/-}$ES cell sphere colonies (Hitoshi et al., 2002) where there were decreases in the self-renewal of isolated NSCs. These studies are consistent with the notion that Hes1 is not necessarily involved in promoting an undifferentiated state.

The suggestion that Hes genes do not function primarily in NSC maintenance is in apparent contrast to the studies by Nakamura et al. (2000) and Ohtsuka et al. (2001), where neurospheres could be generated from embryos mutant for Hes1 and/or Hes5, yet a role for these factors in NSC maintenance was suggested. In both studies, single or double mutant neurospheres were on average smaller; however, the double mutant primary neurospheres could still produce P1 neurospheres (demonstrating selfrenewal). In fact, when neurospheres were normalized for total cell number, Ohtsuka et al. (2001) found that single mutants did not show a reduced number of secondary neurospheres. In our previous study (Shimazaki et al., 2001) and in the current report, reduction in self-renewal is defined as a reduced number of P2 neurospheres from single equivalent sized P1 neuropheres, or as a population normalized for cell number. The observations of smaller primary or secondary neurospheres, reported by Nakamura et al. (2000) and Ohtsuka et al. (2001), could be as readily interpreted as Hes 1 and Hes5 functioning primarily in the maintenance of neural progenitor cells, indeed as suggested by Nakamura et al. (2000), with regard to Hes1. Furthermore, the observation that no neurospheres could be obtained from presenilin $1^{-/-}$/presenilin2 $2^{+/-}$mice (Hitoshi et al., 2002), in contrast to Hes1/Hes5 double mutants, strongly supports the contention that other factors can mediate NOTCH1 signaling actions on NSC self-renewal. Kondo and Raff (2000) reported that both Mash1 and Hes5 are expressed in oligodendrocyte progenitors and may mediate their differentiation. Additionally, Hes5 appears to function in later progenitors of the olfactory neuroepithelium (Cau et al., 2000). Therefore, the marked decrease in Hes 5 expression observed in 3 DIV EGF+CNTF compared with EGF cultures may be the result of an increase in NSCs at the expense of progenitor cells with a limited self-renewal capacity, consistent with our previous findings (Shimazaki et al., 2001) that CNTF supports the maintenance of NSCs by suppressing their restriction to glial progenitors.

Considering that two new Hes genes, Hes6 and Hes7 (Bae et al., 2000; Bessho et al., 2001), have been discovered recently, it is plausible that an as yet unidentified Hes gene mediates the increase in NOTCH1 signaling stimulated by CNTF. Given their observation of neurosphere formation in the Hes1/Hes5 double mutants, Ohtsuka and colleagues (2001) suggest that a splice variant of Hes3 (Hes3b) may contribute to embryonal NSC maintenance. It is also possible that a $S u H / R B P$-J $\kappa$-independent pathway, which may not require Hes, mediates the CNTF-induced increase in NOTCH1 signaling (Shawber et al., 1996; Matsuno et al., 1997; Ordentlich et al., 1998). Future studies of gp130 regulation of Hes genes will likely serve to identify the family member that mediates NOTCH1 regulation of NSC maintenance and self-renewal.

\section{References}

Akira S (1999) Functional roles of STAT family proteins: lessons from knockout mice. Stem Cells 17:138-146.

Alvarez-Buylla A, Herrera DG, Wichterle H (2000) The subventricular zone: source of neuronal precursors for brain repair. Prog Brain Res 127:1-11.

Alvarez-Buylla A, Garcia-Verdugo JM, Tramontin AD (2001) A unified hypothesis on the lineage of neural stem cells. Nat Rev Neurosci 2:287-293.

Artavanis-Tsakonas S, Rand MD, Lake RJ (1999) Notch signaling: cell fate control and signal integration in development. Science 284:770-776.

Austin CP, Feldman DE, Ida Jr JA, Cepko CL (1995) Vertebrate retinal ganglion cells are selected from competent progenitors by the action of Notch. Development 121:3637-3650.

Bae S-K, Bessho Y, Hojo M, Kageyama R (2000) The bHLH gene Hes6, an inhibitor of Hes1, promotes neuronal differentiation. Development 127:2933-2943.

Bessho Y, Miyoshi G, Sakata R, Kageyama R (2001) Hes7: a bHLH-type repressor gene regulated by Notch and expressed in the presomitic mesoderm. Genes Cells 6:175-185.

Brou C, Logeat F, Gupta N, Bessia C, Lebail O, Doedens JR, Cumano A, Roux P, Black RA, Israël A (2000) A novel proteolytic cleavage involved in notch signaling: the role of the disintegrin-metalloprotease TACE. Mol Cell 5:207-216.

Carpenter MK, Cui X, Hu Z, Jackson J, Sherman S, Seiger A, Wahlberg LU (1999) In vitro expansion of a multipotent population of human neural progenitor cells. Exp Neurol 158:265-278.

Casarosa S, Fode C, Guillemot F (1999) Mash1 regulates neurogenesis in the ventral telencephalon. Development 126:525-534.

Cau E, Gradwohl G, Casarosa S, Kageyama R, Guillemot F (2000) Hes genes regulate sequential stages of neurogenesis in the olfactory epithelium. Development 127:2323-2332.

Chambers CB, Peng Y, Nguyen H, Gaiano N, Fishell G, Nye JS (2001) Spatiotemporal selectivity of response to Notch1 signals in mammalian forebrain precursors. Development 128:689-702.

Chen H, Thiagalingam A, Chopra H, Borges MW, Feder JN, Nelkin BD, Baylin SB, Ball DW (1997) Conservation of the Drosophila lateral inhibition pathway in human lung cancer: a hairy-related protein (HES-1) directly represses achaete-scute homolog-1 expression. Proc Natl Acad Sci USA 94:5355-5360.

Conover JC, Ip NY, Poueymirou WT, Bates B, Goldfarb MP, DeChiara TM, Yancopoulos GD (1993) Ciliary neurotrophic factor maintains the pluripotentiality of embryonic stem cells. Development 119:559-565.

De Strooper B, Annaert W, Cupers P, Saftig P, Craessaerts K, Mumm JS, Schroeter EH, Schrijvers V, Wolfe MS, Ray WJ, Goate A, Kopan R (1999) A presenilin-1 dependent gamma-secretase-like protease mediates release of Notch intracellular domain. Nature 398:518-522.

Doetsch F, Alvarez-Buylla A (1996) Network of tangential pathways for neuronal migration in adult mammalian brain. Proc Natl Acad Sci USA 93:14895-14900.

Doetsch F, Caille I, Lim DA, Garcia-Verdugo JM, Alvarez-Buylla A (1999) Subventricular zone astrocytes are neural stem cells in the adult mammalian brain. Cell 97:703-716.

Faux CH, Turnley AM, Epa R, Cappai R, Bartlett PF (2001) Interactions between fibroblast growth factors and notch regulate neuronal differentiation. J Neurosci 21:5587-5596.

Furukawa T, Mukherjee S, Bao Z-Z, Morrow EM, Cepko CL (2000) Rax, hes1, and notch1 promote the formation of Müller glia by postnatal retinal progenitor cells. Neuron 26:383-394.

Gage FH (2000) Mammalian neural stem cells. Science 287:1433-1438.

Gaiano N, Nye JS, Fishell G (2000) Radial glial identity is promoted by notch1 signaling in the murine forebrain. Neuron 26:395-404.

Handler M, Yang X, Shen J (2000) Presenilin-1 regulates neuronal differentiation during neurogenesis. Development 127:2593-2606.

Hatta T, Moriyama K, Nakashima K, Taga T, Otani H (2002) The Role of gp130 in cerebral cortical development: in vivo functional analysis in a mouse exo utero system. J Neurosci 22:5516-5524. 
Hitoshi S, Alexson T, Tropepe V, Donoviel D, Elia AJ, Nye JS, Conlon RA, Mak TW, Bernstein A, van der Kooy D (2002) Notch pathway molecules are essential for the maintenance, but not the generation, of mammalian neural stem cells. Genes Dev 16:846-858.

Kageyama R, Ohtsuka T (1999) The Notch-Hes pathway in mammalian neural development. Cell Res 3:179-188.

Kondo T, Raff M (2000) Basic helix-loop-helix proteins and the timing of oligodendrocyte differentiation. Development 127:2989-2998.

Kwon E-J, Park H-S, Kim Y-S, Oh E-J, Nishida Y, Marsukage A, Yoo M-Ae, Yamaguchi M (2000) Transcriptional regulation of the Drosophila raf proto-oncogene by Drososphila STAT during development and in immune response. J Biol Chem 275:19824-19830.

Logeat F, Bessia C, Brou C, LeBail O, Jarriault S, Seidah NG, Israel A (1998) The Notch1 receptor is cleaved constitutively by a furin-like convertase. Proc Natl Acad Sci USA 95:8108-8112.

Lois C, Alvarez-Buylla A (1994) Long distance neuronal migration in the adult mammalian brain. Science 264:1145-1148.

Matsuno K, Go MJ, Sun X, Eastman DS, Artavanis-Tsakonas S (1997) Suppressor of hairless-independent events in notch signaling imply novel pathway elements. Development 124:4265-4273.

Meredith A, Johnson JE (2000) Negative autoregulation of Mash1 expression in CNS development. Dev Biol 222:336-346.

Morrison SJ, Perez SE, Qiao Z, Verdi JM, Hicks C, Weinmaster G, Anderson DJ (2000) Transient notch activation initiates an irreversible switch from neurogenesis to gliogenesis by neural crest stem cells. Cell 101:499-510.

Morshead CM, Reynolds BA, Craig CG, McBurney MW, Staines WA, Morassutti D, Weiss S, van der Kooy D (1994) Neural stem cells in the adult mammalian forebrain: a relatively quiescent subpopulation of subependymal cells. Neuron 13:1071-1082.

Mumm JS, Schroeter EH, Saxena MT, Griesemer A, Tian X, Pan DJ, Ray WJ, Kopan R (2000) A ligand-induced extracellular cleavage regulates $\gamma$-secretase-like proteolytic activation of notch1. Mol Cell 5:197-206.

Nakamura Y, Sakakibara S, Miyata T, Ogawa M, Shimazaki T, Weiss S, Kageyama R, Okano H (2000) The bHLH gene Hesl as a repressor of the neuronal commitment of CNS stem cells. J Neurosci 20:283-293.

Ohtsuka T, Sakamoto M, Guillemot F, Kageyama R (2001) Roles of the basic helix-loop-helix genes Hes1 and Hes5 in expansion of neural stem cells of the developing brain. J Biol Chem 276:30467-30474.

Ordentlich P, Lin A, Shen C-P, Blaumueller C, Matsuno K, ArtavanisTsakonas S, Kadesch T (1998) Notch inhibition of E47 supports the existence of a novel signaling pathway. Mol Cell Biol 18:2230-2239.

Price JV, Savenye ED, Lum D, Breitkreutz A (1997) Dominant enhancers of Egfr in Drosophila melanogaster: genetic links between Notch and Egfr signaling pathways. Genetics 147:1139-1153.
Redmond L, Oh S-R, Hicks C, Weinmaster G, Ghosh A (2000) Nuclear Notch1 signaling and the regulation of dendritic development. Nat Neurosci 3:30-40.

Reynolds BA, Weiss S (1992) Generation of neurons and astrocytes from isolated cells of the adult mammalian central nervous system. Science 225:1707-1710

Reynolds BA, Weiss S (1996) Clonal and population analyses demonstrate that an EGF-responsive mammalian embryonic CNS precursor is a stem cell. Dev Biol 175:1-13.

Reynolds BA, Tetzlaff W, Weiss S (1992) A multipotent EGF-responsive striatal embryonic progenitor cell produces neurons and astrocytes. J Neurosci 12:4565-4574.

Shawber C, Nofziger D, Hsieh JJ, Lindsell C, Bögler O, Hayward D, Weinmaster G (1996) Notch signaling inhibits muscle cell differentiation through a CBF-1 independent pathway. Development 122:3765-3773.

Shimazaki T, Arsenijevic Y, Ryan AK, Rosenfeld MG, Weiss S (1999) A role for the POU-III transcription factor Brn-4 in the regulation of striatal neuron precursor differentiation. EMBO J 18:444-456.

Shimazaki T, Shingo T, Weiss S (2001) The ciliary neurotrophic factor/leukemia inhibitory factor/gp130 receptor complex operates in the maintenance of mammalian forebrain neural stem cells. J Neurosci 21:7642-7653.

Smith AG, Heath JK, Donaldson DD, Wong GG, Moreau J, Stahl M, Rogers D (1988) Inhibition of pluripotential embryonic stem cell differentiation by purified polypeptides. Nature 336:688-690.

Torii M, Matsuzaki F, Osumi N, Kaibuchi K, Nakamura S, Casarosa S, Guillemot F, Nakafuku M (1999) Transcription factors Mash-1 and Prox-1 delineate early steps in differentiation of neural stem cells in the developing central nervous system. Development 126:443-456.

Tropepe V, Craig CG, Morshead CM, van der Kooy D (1997) Transforming growth factor-alpha null and senescent mice show decreased neural progenitor cell proliferation in the forebrain subependyma. J Neurosci 17:7850-7859.

Turnley AM, Bartlett PF (2000) Cytokines that signal through the leukemia inhibitory factor receptor- $\beta$ complex in the nervous system. J Neurochem 74:889-899.

Williams RL, Hilton DJ, Pease S, Willson TA, Stewart CL, Gearing DP, Wagner EG, Metcalf D, Nicola NA, Gough NM (1988) Myeloid leukaemia inhibitory factor maintains the developmental potential of embryonic stem cells. Nature 336:684-687.

Wolfe MS, Xia W, Moore CL, Leatherwood DD, Ostaszewski B, Rahmati T, Donkor IO, Selkoe DJ (1999) Peptidomimetic probes and molecular modeling suggest that Alzheimer's gamma-secretase is an intramembrane-cleaving aspartyl protease. Biochemistry 38:4720-4727. 